\title{
A propósito da metáfora
}

\author{
Luiz Antônio Marcuschi \\ Universidade Federal de Pernambuco
}

\section{Abstract}

This essay analyzes the metaphor as a specific way of knowing the world and treats it as a chapter of epistemology rather than of Semantics. It reviews concepts already developed by Aristotle and Quintiliano, among others, and refuses to accept metaphor as the transposition of sense or the comparison of two referential domains. It suggests a new view based on the work of Max Black for whom language is seen more as an interactive activity than a system of signs. In sum, from a genetic point of view, it defends the thesis that the metaphor is an a priori synthesis: it is based on the intuitive creative capacity and not on logical or analytic thought. 


\section{NOTA HISTÓRICA PRÉVIA}

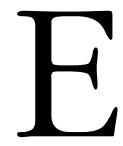

ste ensaio foi escrito em 1975 e, posteriormente, refeito em 1978, com alguns acréscimos, tendo sido publicado na revista

Pórtico, n. 1, 1984, páginas 15-32, do Departamento de Letras da Universidade Federal de Pernambuco, em edição artesanal com 100 exemplares. Sua reprodução neste momento, mais de vinte anos depois de produzido, tem valor sobretudo documental. Não julguei oportuna uma revisão radical do texto trazendo os "avanços" teóricos dos anos 80-90, sobre a metáfora, sob o estímulo de LAKOFF \& JOHNSON (1980)1 (e todos os demais em sua esteira), já que meu texto era de uma década anterior e voltava-se para um certo número de autores olimpicamente ignorados pelos novos "desbravadores" de um dos temas mais tratados no Ocidente. A publicação tem sua motivação mais direta no fato de algumas idéias aqui sugeridas serem atuais, em especial no que respeita às posturas teóricas cognitivistas de FAUCONNIER (1994, 1997), com sua noção de blending (fusão conceitual) entre domínios cognitivos (espaços mentais) básicos como sugestão para o entendimento da metáfora. Mesmo sabendo que várias das observações aqui feitas poderiam ser melhor explicitadas, opto por deixá-las tal como as desenvolvi nos anos 70, adaptando apenas algumas formas de citação. Espero, com isso, repassar sugestões aos colegas interessados no tema, consciente de que antes dos anos 80, já haviam decorrido vinte séculos de reflexão sobre um assunto que os anos 80-90 retomam sob nova visão muitas vezes sem a perspectiva histórica do tema.

Será possível acrescentar algo de interesse à quase ininterrupta investigação da metáfora desde que Aristóteles a definiu em sua Poética? Com efeito, poucos temas experimentam uma tradição teórica tão unitária e fiel como a metáfora. Parece, contudo, perfeitamente 
plausível retomar a problemática, se não para trazer novidades, pelo menos para renovar o debate com colocações ainda pouco exploradas. O intuito do presente ensaio é mostrar a metáfora como algo mais do que um simples fenômeno lingüístico de natureza semântica. Será feita a tentativa de deslocar a metáfora da esfera puramente semântica para a área da teoria do conhecimento. De resto, a metáfora é aqui tomada como um fenômeno que se situa nos limites do dizível dentro da esfera lingüística.

Propor-se uma análise da metáfora nesses termos implica rever alguns aspectos da concepção de linguagem hoje vigente. Em primeiro lugar, tomando a linguagem como fenômeno social, caracteriza-se apenas um de seus lados, ou seja, seu caráter institucional, e pressupõe-se que o uso lingüístico seja constantemente submetido ao consumo da comunidade. Na medida em que o uso se dá como fruto da interação consensual, ele se transforma em regra ou esquema recorrente. Regra é aqui tomada na acepção wittgensteiniana de esquema para alguma ação e por isso mesmo como estrutura pragmática. Com isso a própria noção de criatividade, quando tomada como possibilidade de uso ilimitado de um número finito de regras (léxicas, sintáticas, etc.), vai adquirindo um carácter algorítmico e passa a ser uma escolha possível e definível entre as previstas pelo sancionado sistema abstrato da língua. Daí resulta em parte a pobreza da noção de criatividade em Chomsky, que basicamente se reduz ou equivale a um processo de recursividade. Mas a criatividade parece ser algo mais do que um conjunto de regras projetivas de carácter recursivo: linguagem é algo mais do que um simples cálculo. Criar, em linguagem, é algo mais do que produzir sentenças com base numa série de regras. Assim, numa análise detida do que seja e como funciona a metáfora, aquela noção restrita e empobrecida de criatividade como a encontramos em Chomsky é pouco esclarecedora. A rigor, as investigações chomskyanas sempre passaram por alto sobre a metáfora. O fundamento da criatividade lingüística parece situar-se muito mais no âmbito do não-previsto. Mas qual o carácter desse nãoprevisto, situado em algum misterioso ponto limite? 
Antes de investigarmos esse aspecto crucial, convém que nos detenhamos em outros. Não me refiro ao problema das funções da linguagem, pois este é um detalhe que em nada auxilia na análise da metáfora, uma vez que cabe analisar primeiro o problema epistemológico e não o meramente funcional. A própria caracterização da linguagem como "atividade simbólica" de pouco serve, como bem frisa Coseriu quando observa que "o adjetivo simbólico não classifica a atividade lingüística segundo sua natureza, não nos diz que atividade é a linguagem, mas apenas caracteriza, indica de que tipo são seus elementos, os momentos em que se articula" (COSERIU, 1977:71). Mais do que este, o primeiro momento constitutivo é o da atividade cognoscitiva que se realiza em símbolos. Os signos lingüísticos são o material de que se serve o homem em sua atividade cognoscitiva, de modo que a criatividade está na contínua seleção cognoscitiva que se opera face à realidade e não na combinação dos símbolos como tal. Estes não passam de um recurso institucionalmente garantido para exercerem aquela atividade primeira. Analisando essa atividade em sua gênese, trata-se de ver mais o processo do que o produto. Isto levaria a ter que desenvolver um estudo das relações entre pensamento e linguagem, uma vez que é nessa relação que se desenvolve o discurso. Contudo, essa proposta fica aqui apenas apontada e não será analisada, pois nos levaria a uma digressão muito longa, cujos resultados poderiam não ser os mais satisfatórios.

Retornando à questão lançada acima, em que se indagava pelo caráter do não-previsto como o traço da criatividade, pode-se agora dizer que a criatividade não se acha ao nível do uso de símbolos lingüísticos, mas ao nível da atividade que produz o conhecimento que os símbolos transmitem. Neste sentido, a própria criatividade vai determinando-se como um processo de violar os símbolos, dandolhes algo que no sistema abstrato não estava previsto. É por isso que me parece não haver criatividade em todos os atos de fala, mas apenas naqueles em que algo mais do que a convenção, o uso e o saber comum estejam presentes. Criar é algo mais do que simplesmente usar a linguagem em situações contextualmente novas. É fazer 
com que a linguagem consiga transmitir aquilo que foi criado à sua revelia e à margem do instituído.

Tendo em vista estas posições, partiremos aqui da premissa de que a metáfora não é apenas um simples recurso lingüístico catalogado entre os tropos ou figuras de linguagem, mas um modo específico de conbecer o mundo, que, ao lado do conhecimento lógico-racional, tem sua razão de ser e instaura uma série de valores de outra maneira perdidos ou não-encontrados. ${ }^{2}$ Assim, tentaremos mostrar que a metáfora é essencialmente mais do que uma simples transferência de significado baseada em certos artifícios semanticamente explicáveis, e, muito mais do que uma simples comparação abreviada. Na verdade, ela pode ser tida como ponto de apoio para uma análise de capacidade criativa espontânea do indivíduo, sendo então, apenas do ponto de vista operacional, uma transposição de significado, mas, do ponto de vista genético e psicológico, ela seria a criação de novos universos de conhecimento. Criaria, pois, uma realidade nova.

Como assinalam FONZI \& SANCIPRIANO (1975:3), 3 "a metáfora é a um tempo mágica e lógica, subjetiva e objetiva, interior e comunicativa e a sua força reside no próprio fato de nela se conciliarem pólos diferenciados". A esses pólos diferenciados fundidos, que constituem a base da metáfora, chamarei mais adiante de fusão de campos semânticos diversos irredutíveis a relações lógicas. Substitui-se, assim, a noção de transposição e comparação pelas de composição e criação.

Embora surja no âmbito da linguagem, a metáfora não permanece presa a ela ao criar uma realidade nova não puramente lingüística. ${ }^{4}$ Não é possível, portanto, penetrar a metáfora com recursos apenas lingüísticos, dado que ela se submete às categorias de denotação, conotação ou outras semelhantes. Não interessa no momento saber que tipo de realidade a metáfora cria, importa apenas que, seja ela religiosa, estética, poética etc., é sempre uma realidade intersubjetivamente comunicável.

Apesar de metáfora e magia terem muito em comum, não devem ser identificadas. A magia é um modo de conhecer o mundo 
a fim de agir sobre ele, influenciando-o, ao passo que a metáfora é um modo novo de conhecer e comunicar o mundo assim conhecido. Ela é, de certa forma, um recurso reestruturador da realidade, criando novas áreas de experiência que fogem ao indivíduo restrito à realidade puramente factual. É em parte isso que leva todas as correntes lingüísticas e filosóficas de cunho positivista a não tratarem a metáfora ou simplesmente a descartá-la.

Mesmo admitindo ser a metáfora uma questão dentro da lingüística, poucos semanticistas preocupam-se seriamente em estudá-la. Katz, Fodor e muitos outros como Greimas ou os mais clássicos como Bloomfield baseiam suas análises na impossibilidade de abordagem da metáfora. Ela é, no máximo, uma anomalia semântica não-enquadrável em qualquer esquema de teorias científicas. Até em Teoria Literária a metáfora é tida como uma licença poética, um recurso justificável dentro de postulados racionais, mas realizável fora deles, e nunca plenamente explicado. A metáfora parece dividir o homem num ser que possuísse uma razão com duas naturezas. Ora, pensando assim, nada se consegue, apenas relegase a metáfora ao plano do inexplicável dentro da ordem lógica. Isso, porém, é muito cômodo e nada resolve, apenas adia ou descarta.

Dar algo a conhecer através da linguagem não é ainda afirmar esse algo como existente. A existência é uma instância independente da linguagem e, mais do que isso, não é uma qualidade predicável. Aliás, esse é um argumento fundamental, na Crítica da Razão Pura de Kant, na análise das antinomias da prova da existência de Deus. Por isso mesmo não tratamos aqui de questões gnosiológicas com base em alguma ontologia qualquer, mas à margem de todas elas. Mas, embora ainda não haja uma ontologia da metáfora, pode-se supor que nos fundamentos da metáfora estão bases da experiência empírica que a consciência acumulada reserva para elaborar estruturas e universos além da própria experiência. Não há dúvida de que "o além da experiência" tem sua base na experiência. Contudo, a metáfora não obedece à gramática da experiência empírica e é um campo novo de experiência. Que espécie de expe- 
riência é essa e como ela se constitui é o problema maior aqui enfocado.

A metáfora não é constituída no respeito à realidade, como acontece, por exemplo, com as operações da linguagem denotativa. Não é, portanto, uma operação lógica, mas recorre essencialmente a uma espécie de intuição pré-lógica (talvez seja um pensamento prélingual assumindo formas lingüísticas!). Impossível, pois, dar um algoritmo para a construção de metáforas. Falharão, assim, a maioria das técnicas para, em paráfrases, dar o significado literal de metáforas, como ainda veremos detalhadamente, pois as tentativas de "tradução" de metáforas para o plano literal sempre consideram que a metáfora parte de uma comparação à qual ela poderia ser reduzida. No entanto, uma das teses básicas aqui defendidas será a de que a metáfora não é fruto da comparação, e sim, no máximo, base para uma comparação a posteriori. A ordem psicológica tem aqui prioridade sobre a ordem lógica. É a metáfora que funda a comparação e não o contrário.

Uma última observação introdutória se faz aqui necessária. Os estudos sobre a metáfora foram realizados preponderantemente nas investigações literárias no campo da poética, sendo que isto a revestiu de um certo halo preconceituoso, obscurecendo sua função no plano da vida cotidiana. O presente estudo não se aterá apenas ao plano literário e irá também ao da vida cotidiana. Não se verá a metáfora como propriedade de eleitos e eruditos, mas como o fato mais normal da vida cotidiana. Ela é inclusive o estado normal da criança, que convive com a palavra do mesmo modo que convive com os objetos. Uma convivência com o mundo muito aproximada daquela dos poetas. Sob este aspecto, seguindo o psicólogo russo VYGOTSKI (1974) ${ }^{5}$, diríamos que a metáfora é anterior à razão e serve de meio para aferir a capacidade criativa natural do homem.

Tomando essa posição como ponto de partida, na metáfora, não teríamos, a esse nível primeiríssimo, a dicotomia significante significado, pois esses seriam do domínio da linguagem conceitual. Daí falarmos, no início, de uma misteriosa esfera do "não-previsto" 
como o domínio próprio da metáfora. Desse modo, liberamos a metáfora como uma função primitiva da linguagem, onde a palavra é a coisa. A metáfora seria como que o foco para se identificar um mundo que a linguagem conceitual apenas tenta "reorganizar". Daí também termos falado na necessidade de uma reconceituação de linguagem para podermos pensar a metáfora. Invertendo os pólos, a metáfora ultrapassaria a discussão semiótica e criaria um domínio próprio de investigação. Daí a vontade inicial de retirar a metáfora do contexto da lingüística.

Não obstante as observações acima, é impossível negar que a metáfora se nos apresenta num primeiro momento como um ‘fenômeno lingüístico", pelo menos ao nível da manifestação superficial. Por isso ela desempenha, para muitos autores, um papel extraordinário no esclarecimento da dimensão, limites e possibilidades da própria língua. Não será esse, no entanto, nosso interesse motor: ${ }^{6}$ gostaríamos de saber como ela se constitui e qual sua epistemologia.

Desde que Aristóteles caracterizou a palavra "metáfora" e forneceu pela primeira vez sua definição e teorização na Poética, surgiram numerosos estudos sobre o tema. ${ }^{7}$ A maioria dos autores consideram a metáfora como essencial à língua e muitos deles vêem nela sua maior riqueza. F. Mauthner, por exemplo, considera que a língua se desenvolve através de metáforas, que a própria língua é uma metáfora, de tal modo que, no entender desse autor, poderíamos elucidar melhor o "desenvolvimento lingüístico" através de metáforas, do que pelo recurso à etimologia (MAUTHNER, 1923:451454 e 465ss). "Que a metáfora é o princípio onipresente da língua, já pode ser notado na simples observação diária”, lembra I. A. Richards, que considera impossível falar três frases sem que nelas apareça pelo menos uma metáfora (RICHARDS, 1950:92).

Com efeito, parece não ser exagero afirmar que grande parte de nossa linguagem cotidiana baseia-se em metáforas "conscientes" ou já "congeladas", na terminologia de GOODMAN (1968:77-85). Abaixo, estão alguns exemplos de "metáforas", umas já "esmaecidas" 
e quase sem força, tendo seu significado já dicionarizado, o que torna aliás necessária uma tipologia da metáfora, a fim de se decidir quando se está ou não em face de metáforas ou "metáforas".

Esse passo metodológico é importante para o trabalho.

O pano de fundo de seus argumentos não me é claro.

O borizonte de sua palestra foi muito limitado.

Os dias escuros de sua vida já passaram.

Como linha de argumentação ele escolheu Demócrito.

Os terroristas explodiram a ordem.

O céu ficou triste no dia da sua partida.

Fiquei desnorteado com a resposta de meu amigo.

Geralmente não tenho sonhos pesados.

É por isso que Jean Paul podia afirmar que a língua não passa de um "dicionário de metáforas empalidecidas" (PAUL, 1804:184). Contudo, J. Derbolav observa que, apesar de muitos autores afirmarem o mesmo que J. Paul, "ainda inexiste uma teoria filosófica convincente da metáfora" (DERBOLAU, 1949:80). Observando bem os exemplos acima, vemos que eles não nos espantam e dão-nos a conhecer algo muito normal, facilmente compreensível. É justamente aí que reside o problema. Como é isso possível? A normalidade do produto nada diz ainda sobre a natureza do processo de sua formação, pois do efeito jamais se chega à causa.

Já lembramos que há muitos autores, principalmente entre os neopositivistas e os modernos filósofos das ciências, que não dão grande importância à metáfora. Metáfora é, para eles, uma categoria pertencente à Poética e Estética, mas insignificante e até mesmo desnorteante para a ciência. Expressões metafóricas podem ser facilmente mal-entendidas, não possuem conteúdo definido, são expressões poéticas ou emotivas e fundadas em bases subjetivas. Mas, acentua categoricamente I. A. Richards, até mesmo na linguagem rigorosa das ciências bem fundamentadas, é difícil eliminar ou 
evitar as metáforas. E nas ciências "semi-técnicas" como Estética, Política, Sociologia e Ética ou Filosofia é, inclusive, difícil constatar quando se está em presença de uma expressão metafórica ou não (RICHARDS, 1950:92).

Entremos agora na análise da posição teórica que toma a metáfora como transposição do significado. Desde Aristóteles que o termo "metáfora" - que em grego ainda não era uma palavra estrangeira, como observa jocosamente F. Mauthner - é utilizado para a transposição de uma palavra com certo significado para um contexto que lhe seria originalmente estranho. ${ }^{10}$ Esta teoria da metáfora mais freqüentemente aceita é hoje, com razão, posta em dúvida por muitos autores. Com o início dos estudos críticos da linguagem, especialmente no final do séc. XIX e, mais intensamente, depois, com a Filosofia Analítica, o problema foi deslocado para um leque mais amplo.

A concepção aristotélica da metáfora como "transposição do significado de uma palavra" foi combatida com grande maestria pelo filósofo alemão H. Lipps (LIPPS, 1958:66 e ss.) nos seguintes termos. Admitindo que a metáfora seja a transposição do significado de uma palavra de um contexto para outro - implicando com isso a contraposição de significados "autênticos" versus "transpostos" -, o que quer dizer então "significado" de uma palavra, pergunta H. Lipps. Se fôssemos responder a essa indagação com a teoria do significado de Wittgenstein (PU \43), poderíamos dizer que o significado de uma palavra é a gramática de seu uso na língua. Mas com isso estaríamos dificultando um bocado a criteriologia para a caracterização da metáfora. Algo parecido argumenta também H. Lipps, ao dizer que o significado se pleni-fica (voll-zieht) apenas no contexto de uso. Explode-se, por exemplo, um edifício, uma ponte, etc. com dinamites, mas um orador explode, com palavras, uma reunião, como também operários explodem governos com greves, etc. Apesar de todas essas divergências, tudo isso é "explodir" (LIPPS, 1958:67, com adaptações). Daí afirmar Lipps não haver "significado originário", mas "origem de um significado", o que torna a definição da metáfora como "transposição do significado de uma palavra" 
totalmente inadequada (LIPPS, 1958:69-72). Assim, de duas uma: ou não estamos em presença de uma metáfora, e sim de termos polissêmicos com vários usos, ou então metáfora é algo de curta duração e sempre destinada a se tornar natural. Mas será que a metáfora é apenas impacto? Seria a assimilação do impacto o princípio de enriquecimento da linguagem?

De fato, expressões metafóricas sugerem aspectos que as palavras com seu "significado literal" não podem apresentar. É com razão, portanto, que H. Blumenberg afirma que o "campo de uso da metáfora é o lugar da formação de conceitos de outro modo impossíveis, malogrados ou não concretizados" (BLUMENBERG, 1971:171). Expressões tais como, "a recepção foi fria", ou, "o dia está triste", dizem muito mais do que se quiséssemos obter, com o mesmo efeito cognitivo, este conteúdo emotivo ou subjetivo através de descrições (literais).

É possível, no entanto, que uma expressão metafórica não tenha significado literal, como mostra $\mathrm{H}$. Lipps mediante a palavra animalesco. 'O 'animalesco' (tierisch) caracteriza um comportamento humano. Mas foi transferido para este sentido? Provavelmente não, pois o próprio animal não é 'animalesco'. 'Animalesco' caracteriza uma deficiência que apenas quando vista à luz das exigências humanas torna-se uma deficiência" (LIPPS, 1958:69-71). Consideremos outro exemplo, também de $\mathrm{H}$. Lipps, que preenche as condições das relações subjetivas fora do campo de significado original. "Para caracterizar a ignorância de alguém, o denominamos 'um burro' ou 'um camelo'. Isso, porém, com o qual o comparamos, não é tomado simplesmente como portador da mesma característica. Os camelos não são de forma alguma ignorantes; um burro não é 'um burro' no mesmo sentido que um homem" (LIPPS, 1858:73). Fica com isso comprovado, segundo H. Lipps, que não tem fundamento pleno a noção de metáfora como transposição de sentido.

Vonessen, outro autor alemão, que, apesar das críticas a Aristóteles, ainda fica preso à sua teoria, encara a "transposição" como uma "mudança espacial" (Ortsveränderung) da palavra, isto é, a metáfora seria a mudança do lugar lógico duma palavra ao passar 
de um uso "próprio" a um "impróprio". Segundo ele, a metáfora é "apenas um caso especial dessa transposição e não a transposição pura e simplesmente" (VONESSEN, 1959:309 e 402). Para Vonessen, a transposição continua funcionando como esquema para o conceito de metáfora, e ele frisa que ainda hoje, como desde Aristóteles, essa teoria permanece em vigor com pequenas variações.

Max Black, ao lado de I. A. Richards, forneceu uma teoria bastante lúcida da metáfora, partindo de um princípio diverso do da transposição, a fim de desenvolver uma teoria da interação (interaction theory) (BLACK, 1962:25-47). Mas, a nosso ver, apesar de salvar-se da transposição, ele cai de certo modo na comparação (analogia como base). De resto, ela garantiria um bom conhecimento a respeito das possibilidades de utilização e das fronteiras da metáfora (BLACK, 1962:38).

M. Black, que procura desenvolver uma "gramática lógica" para a metáfora, tenta buscar respostas às seguintes questões: como podemos saber que estamos diante de uma metáfora? Temos critérios para tanto? Podemos traduzir metáforas em expressões literais? Quais são as relações entre metáfora e comparação? Em que sentido uma metáfora é criativa? Enfim, o que pretendemos quando usamos metáforas? (BLACK, 1962:25)

Segundo o autor, em muitas situações, nos deparamos com "casos claros" de metáforas facilmente reconhecíveis, como nesses exemplos:

Os terroristas explodiram a ordem.

Foi um dia triste.

Sua filha era o sol de sua vida.

As palavras explodir, sol e triste formariam aqui o foco da metáfora e o restante seria a estrutura, o arcabouço literal que a abrangeria. M. Black parte de I. A. Richards, que utilizava os termos tenor ("teor") (que Black chamou de focus) e vebicle ("veículo") (que Black chamou de estrutura frame). A metáfora seria a fusão dos dois numa unidade (BLACK, 1962:28 e RICHARDS, 1950:96-99). O grande 
problema que aí surge é o da tradução de uma metáfora para outra língua. Suponhamos a seguinte expressão:

The chairman plowed through the discussion.

A palavra plowed seria aqui o foco da metáfora e o restante estaria sendo usado em sentido literal. Admitindo que se pudesse traduzir isso para outra língua, a metáfora deveria ficar preservada na tradução. Se ela fosse preservada, diríamos então que a metáfora estava baseada no significado (RICHARDS, 1950:100 e BLACK, 1962:38-40). Mas, qualquer tradução, tanto dentro como fora do inglês, seria inevitavelmente um empobrecimento da metáfora, pois deveria decidir-se por uma interpretação determinada.

Assim, de acordo com Black, a metáfora constituir-se-ia na interação de dois contextos diversos, um dos quais seria o focus. Na interação desses dois sistemas diversos (o metafórico e o literal) situar-se-ia a essência da metáfora. No exemplo de Black, "o homem é um lobo", dar-se-ia um caso típico da fusão de dois sistemas num só. Nesse exemplo teríamos dois sujeitos: um sujeito lógico (gramatical) homem e um sujeito "secundário", o lobo. Não haveria predicação, uma vez que não estaríamos atribuindo ao homem a propriedade lobo, nem seria uma adjetivação de lobo que estaria recebendo propriedades humanas. O ponto de partida é a pressuposição de que o significado literal das duas expressões implicadas seria conhecido e o contexto de cada um desses signi-ficados constituiria o "sistema associado de lugares-comuns". Deste modo, o sistema-lobo (carnívoro, enganador, faminto, etc.) é colocado em relação com o sistema-homem (com todas as suas propriedades), no qual surge então algo novo, que é o sentido metafórico. Esta seria uma solução muito plausível, se não fosse problemática, na maioria das ocorrências, ao trazer para o caso uma comparação. Essa compa-ração se dá como uma transferência das propriedades do sujeito secundário no interior do sujeito principal. Apesar de superar a transposição de significado como pilar da metáfora, Black deixa lugar para uma possível comparação, o que transforma sua posição em insatisfatória. 
Portanto, se a noção de fusão de campos semânticos poderia ser uma boa saída para a questão da transposição de sentido, surge nela o impasse de superar a comparação como fonte para a metáfora. Na verdade, é possível que não se consiga fugir totalmente da metáfora como um fenômeno que tenha base na comparação, mas cremos que não é possível afirmar que todas as metáforas têm base na comparação. A noção de metáfora como comparação foi introduzida por Quintiliano em sua Institutiones Oratoriae, que, ampliando o conceito aristotélico de metáfora, disse: "metaphora brevior est similitudo". Massaud Moisés, em seu Dicionário de termos literários (MOISÉS, 1974:323-333) (de resto, uma obra muito instrutiva), refere, para exemplificar a posição de Quintiliano por ele endossada, um verso de Mário de Sá-Carneiro:

"Na minha dor quebram-se espadas de ânsia,

Gomos de luz em trevas se misturam.

As sombras que eu dimano não perduram,

Como ontem, para mim, Hoje é distância."

Em seu comentário, diz Massaud Moisés o seguinte: "Observese que os dois primeiros versos contêm duas metáforas de comparação implícita, enquanto o derradeiro segmento apresenta uma metáfora de comparação explícita; em ordem, teríamos: 'Para mim, Hoje é distância como Ontem (é distância)” (MOISÉS, 1974:332). Para M. Moisés, “a comparação evidenciada pela partícula 'como' é metafó-rica precisamente porque instaura um sentido novo por meio da justaposição identificadora dos dois membros da equação”. Minha tendência é, ao contrário, postular que justamente aquele comoé um ladrão da metáfora; ele tira a força da metáfora e cria um símile com certa força expressiva, mas não é metáfora no sentido estrito do termo. O primeiro verso - "Na minha dor quebram-se espadas de ânsia" - traz indubitavelmente uma metáfora forte que não pode ser reduzida a uma comparação, porque faltariam os termos da equação e também porque não pode ser traduzida em termos literais 
numa paráfrase interpretativa, uma vez que perderia toda sua força cognoscitiva, trivializando-se. Criou o poeta, por isso mesmo, um universo novo de comunicação, não redutível a outra instância, não confinável ao âmbito do lingüístico, nem abarcável com postulados de interpretação lógica.

São metáforas desse tipo, como muitas das que encontramos em Rimbaud e na maioria dos poetas modernos, que me levam a negar a possibilidade de definir a metáfora como uma comparação abreviada, no sentido de Quintiliano. Quando RIMBAUD (1957:80), por exemplo, diz em seu poema, Após o Dilúvio, em Iluminações:

"Desde então, a Lua ouviu os chacais berrando nos desertos de tomilho

- e as éclogas de tamancos rosnavam no pomar"11

podemos indagar: qual a base que serve de comparação para as metáforas aqui presentes? A surpresa que tais expressões metafóricas causam e a confusão que geram no leitor será tanto maior quanto mais rico o mundo que elas revelam e quanto mais intraduzível for esse mundo.

Segundo GOODMAN(1968:89), uma metáfora deve ser "eficaz" e essa qualidade baseia-se em algo. Esse algo é o efeito-surpresa que ela causa. Aquele elemento não-previsto a que nos referíamos no início e que evidencia um momento de criatividade. É quase possível dizer que a metáfora, no seu mais legítimo sentido, tem uma finalidade em si e não exige compreensão definida e sim apenas sugerida. O conhecimento novo que ela nos sugere é fornecido por uma intuição e por um pensamento que não se baseia em comparação alguma e foge à explicação lógica. Neste sentido a metáfora como que produz a comparação e não a formula simplesmente: a comparação é, no máximo, um resultado da metáfora e não o contrário. Quando ouvimos uma expressão metafórica tão corriqueira como "o dia está triste", não se dá primeiro uma comparação e então surge a metáfora. É precisamente o contrário; a comparação é um fenômeno post festum. Atribuir ao dia uma propriedade antropomór- 
fica é produto de uma intuição cognitiva que nos leva a interpretar uma comparação. De resto, o tertium comparationis da equação não é tão facilmente encontrável, ao nível racional-lógico, pois o homem fica triste de outra forma que o dia. Basicamente, é um sistema cognoscitivo que entra em ação e não uma atividade lógica.

Caso colocássemos a comparação como base para a metáfora, estaríamos dando-lhe um suporte lógico, um esquema estruturador com fins explicativos. Mas ela é uma força cognitiva ativada por mecanismos impenetráveis por instrumentos elaborados em função da análise do saber normal. Assim, a comparação é uma forma de violação da metáfora; é um momento de racionalização indevida dentro de uma esfera que se quer indevassável. Justamente por isso Aristóteles, nos Analitica Posteriora, alija a metáfora do discurso científico, pois julga as expressões metafóricas impróprias para argumentar cientificamente. ${ }^{12}$

Metáfora é síntese a priori: funda-se na capacidade criadora intuitiva, e não num pensamento analítico ou lógico. Quando se fala em "lógica da metáfora", entende-se com isso apenas seu peculiar modo de conhecer. A comparação como razão explicadora da gênese da metáfora funciona apenas como recurso da apropriação racional. Neste sentido, o jogo da intuição metafórica, ao contrário do que se costuma pensar, é mais denso na medida em que menos se expõe à abstração. Ela é um pensamento concreto e sem capacidade generalizadora.

Veja-se o seguinte verso extraído da obra Tambor Cósmico, de César Leal, em seu poema Metalinguagem (LEAL, 1978:50):

“A linguagem é rosto é cabeça e braço serpente bailarina viola motor a linguagem derrapa se quebra e se afoga a linguagem é Amor".

Seria inútil tentar estabelecer os elos da presumível comparação que serviu de base ao poeta. Momentos como este dão ao poema força e vigor, tornando-o concreto e palpável. Enquanto a comparação distancia os objetos ao estabelecer relações entre eles, a metáfora 
funde e impossibilita a penetração das partes. A metáfora não se esgota, pois, nos limites da linguagem nem no âmbito das relações lógicas. Ela é, em certo sentido, a dimensão mais radical da linguagem, uma vez que é a convivência direta da linguagem com o mundo e não uma convivência com o mundo pela razão. Com isto, tornamonos infiéis aos propósitos iniciais de resgatar a metáfora para o plano da teoria do conhecimento, pois tudo indica que o conhecimento por ela gerado tem estruturas que as usuais teorias do conhecimento ainda desconhecem.

\section{NOTAS}

${ }^{1}$ Esses autores não citam Aristóteles nem Quintiliano ou outros da tradição. A obra mais antiga por eles citada é um texto de Frege de 1982, em tradução inglesa de 1966.

${ }^{2}$ Não estou certo de se podemos incluir a metáfora entre os tropos, na medida em que definimos o tropo como uma figura de linguagem em que se observa um desvio ou mudança de significado. O estudo a seguir busca evidenciar a possibilidade de tratar a metáfora à margem dos tropos.

${ }^{3}$ Esse pequeno estudo é uma valiosa análise da metáfora na idade evolutiva da criança. Além disso, é também um ótimo trabalho sobre a metáfora sob o ponto de vista do conhecimento psicológico.

${ }^{4}$ Algumas das observações a seguir procedem do estudo aqui citado na nota acima.

${ }^{5}$ Cf. especialmente os primeiros capítulos.

${ }^{6}$ Um exemplo de estudo que poderia explorar essa linha de investigação encontrase no ensaio de COSERIU (1977).

${ }^{7}$ Como confirmação dessa assertiva indicamos aqui o precioso levantamento de SCHIBLES, Metaphor: An Annotated Bibliography and History, 1971. Este continua sendo ainda hoje o mais completo levantamento bibliográfico de que se dispõe sobre o assunto. Do mesmo mesmo autor, temos: Analysis of metaphor in the light of W. M. Urban's Theories, 1971. Além disso, outras obras são interessantes, como: RICHARDS, The philosophy of Rhetoric, 1950, especialmente p.89-132. BLUMENBERG, Paradigmen zu einer Metaphorologie, 1960. E ainda do próprio BLUMENBERG, Beobachtungen an Metaphern, 1971. MAUTHNER, Beiträge zu einer Kritik der Sprache, 1923. O texto sobre a metáfora encontra-se na tese de doutoramento de LIEB, Der Umfang des historischen Metaphernbegriffs, 1964. BLACK, Models and Metaphors, 1962. E ainda GOODMAN, Languages of Art, 1968. 
${ }^{8}$ Muito bem observa Derbolav que a metáfora é um dos Grundlagenprobleme, que não pode ficar circunscrito aos limites do sistema em que se manifesta. Já que a metáfora situa-se na esfera lingüística e como dela não podemos sair, corremos o risco de uma "petitio principii" ao analisá-la: fala-se metaforicamente sobre a metáfora. Ou, segundo observa Goodman, teríamos a ver aí com um processo de bigamia ou um erro categorial calculado.

${ }^{9}$ BLACK, 1962:25 e ss; também a controvérsia BLUMENBERG, 1960:161 e ss, ou RITTER, 1971, V.I, VIII e ss. Ou ainda BEARDSLEY, 1967, V. V, 285-289.

${ }^{10} \mathrm{Cf}$. a Poética de Aristóteles, onde são dados os termos da equação.

${ }^{11}$ Damos o texto na tradução e não no original, justamente para estabelecer, mesmo numa possível interpretação, o impacto que o texto causa. De resto, não se veja aí nenhuma tentativa de nossa parte de interpretar Rimbaud ou de dizer que é ininterpretável.

${ }^{12}$ Aristóteles, Analytika Posteriora, 97b 37-39 ou também nos Tópicos, 158b 1017 ou 139b 34-36.

\section{REFERÊNCIAS BIBLIOGRÁFICAS}

BEARDSLEY, M. C. The Encyclopedia of Philosophy, v. V, 1967.

BLACK, Max. Models and metaphors. Studies in Language and Philosophy. New York: Ithaca, 1962.

BLUMENBERG, Hans. Paradigmen zu einer Metaphorologie. In: Archiv für Begriffsgeschichte, Bonn, v. IV, 1960.

BLUMENBERG, Hans. Beobachtungen an Metaphern. In: Archiv für Begriffsgeschichte, Bonn, v. XV, p.161-215, 1971.

COSERIU, Eugenio. La creacion metaforica en el lenguaje. In: El hombre y su lenguaje. Madrid: Editorial Gredos, 1977.

DERBOLAV, J. Das metaphorische in der Sprache. Beitrag zu einer dialektischgrenzbegrifflichen Sprachphilosophie. In: Philosophie der Wirklichkeitsnähe. Viena: Verlag A. Sexl, 1949.

FONZI, Ada, SANCIPRIANO, Elena Negro. La magia delle parole: alla riscoperta della metafora. Torino: Giuliano Einaudi, 1975.

FAUCONNIER, Gilles. Mental spaces. 2. ed. Cambridge: Cambridge University Press, 1994.

FAUCONNIER, Gilles. Mappings in thought and language. Cambridge: Cambridge University Press, 1997. 
GOODMAN, Nelson. Languages of art. An approach to a theory of symbols, 1968.

LAKOFF, George, JOHNSON, Mark. Metaphors we live by. Chicago: The University of Chicago Press, 1980.

LEAL, César. Tambor cósmico. 2. ed. Rio de Janeiro: Tempo Brasileiro, 1978.

LIEB, Hans H. Der Umfang des historischen Metaphernbegriffs. Köln: 1964 (Dissertação de Filologia).

LIPPS, Hans. Die Verbindlichkeit der Sprache. Arbeiten zur Sprach-philosophie und logik. 2.ed. Frankfurt / Main: Vittorio Klostermann, 1958.

MAUTHNER, F. Beiträge zu einer Kritik der Sprache. 2. ed. Leipzig Felix Meiner Verlag, 1923, 3v.

MOISÉS, Massaud. Dicionário de termos literários. São Paulo: Cultrix, 1974.

PAUL, Jean. Vorschule der Ästhetik. Kleine Nachschule zur ästhetischen Vorschule. Munique: Carl Hanser Verlag, 1804.

RICHARDS, Irving A. The philosophy of Rhetoric. 2. ed. New York: Oxford University Press. 1950.

RIMBAUD. Trad. Ledo Ivo, Rio de Janeiro: Civilização Brasileira, 1957.

RITTER, J. Historisches Wörterbuch der Philosophie . Leipzig: 1971, v.I.

SCHIBLES, Warren A. Metaphor: an annotated bibliography and bistory. Wisconsin: The Language Press, 1971a.

SCHIBLES, Warren A. Analysis of metaphor in the light of W. M. Urban's Theories. The Hague, Mouton, 1971b.

VONESSEN, F. Die ontologische Struktur der Metapher. Zeitschrift für philosophische Forschung, 1959, v. XIII.

VYGOTSKI, I.S. Denken und Sprechen. Nerdlingen: S. Fischer Verlag, 1974.

WITTGENSTEIN, Ludwig. Philosophische Untersuchungen. [PU] In: Schriften 1. Frankfurt am Main: Suhrkamp, p. 279-544, 1969. 